\title{
Epac activation inhibits IL-6-induced cardiac myocyte dysfunction
}

\author{
Huiling $\operatorname{Jin}^{1} \cdot$ Takayuki Fujita $^{1} \cdot$ Meihua Jin $^{1,2} \cdot$ Reiko Kurotani $^{1,3}$. \\ Yuko Hidaka $^{1}$ - Wenqian Cai ${ }^{1} \cdot$ Kenji Suita $^{1} \cdot$ Rajesh Prajapati $^{1} \cdot$ Chen Liang $^{1}$ • \\ Yoshiki Ohnuki ${ }^{4}$ Yasumasa Mototani ${ }^{4}$ Masanari Umemura ${ }^{1}$ Utako Yokoyama ${ }^{1}$. \\ Motohiko Sato $^{1,5} \cdot$ Satoshi Okumura ${ }^{1,4} \cdot$ Yoshihiro Ishikawa ${ }^{1}$
}

Received: 17 September 2016/Accepted: 25 November 2016/Published online: 19 December 2016

(C) The Author(s) 2016, corrected publication 2019

\begin{abstract}
Pro-inflammatory cytokines are released in septic shock and impair cardiac function via the Jak-STAT pathway. It is well known that sympathetic and thus catecholamine signaling is activated thereafter to compensate for cardiac dysfunction. The mechanism of such compensation by catecholamine signaling has been traditionally understood to be cyclic AMP-dependent protein kinase (PKA)mediated enforcement of cardiac contractility. We hypothesized that the exchange protein activated by cAMP (Epac), a newly identified target of cAMP signaling that functions independently of PKA, also plays a key role in this mechanism. In cultured cardiac myocytes, activation of Epac attenuated the inhibitory effect of interleukin- 6 on the increase of intracellular $\mathrm{Ca}^{2+}$ concentration and contractility
\end{abstract}

H Jin, T Fujita and M Jin contributed equally to this work.

Satoshi Okumura

okumura-s@tsurumi-u.ac.jp

$\triangle$ Yoshihiro Ishikawa

yishikaw@yokohama-cu.ac.jp

1 Cardiovascular Research Institute, Yokohama City University Graduate School of Medicine, 3-9 Fukuura, Kanazawa-ku, Yokohama 236-0004, Japan

2 Department of Cardiac Physiology, National Cerebral and Cardiovascular Center Research Institute, 5-7-1 Fujishirodai, Suita-shi, Osaka 565-8565, Japan

3 Biochemical Engineering, Faculty of Engineering, Yamagata University, 4-3-16, Jonan, Yonezawa, Yamagata 992-8510, Japan

4 Department of Physiology, Tsurumi University School of Dental Medicine, 2-1-3 Tsurumi, Tsurumi-ku, Yokohama 230-8501, Japan

5 Department of Physiology, Aichi Medical University, 1-1 Yazakokarimata, Nagakute, Aichi 480-1195, Japan in response to isoproterenol, most likely through inhibition of the Jak-STAT pathway via SOCS3, with subsequent changes in inducible nitric oxide synthase expression. These findings suggest a new role of catecholamine signaling in compensating for cardiac dysfunction in heart failure. Epac and its downstream pathway may be a novel target for treating cardiac dysfunction in endotoxemia.

Keywords Epac · cAMP · Catecholamine - Contractility · Cytokine $\cdot$ Jak-STAT

\section{Introduction}

The classic cyclic AMP (cAMP)/protein kinase (PKA) pathway is a major regulator of cardiac function. Norepinephrine released from the synaptic terminals binds to $\beta$ adrenergic receptors, leading to activation of adenylyl cyclase and thus the production of cAMP [1, 2]. cAMP, a major second messenger, activates PKA, initiating cascades of phosphorylation reactions of molecules involved in myocyte contraction [3]. The final outcome of norepinephrine/cAMP signaling is to increase cardiac contractility. It is well known that sympathetic nerve activity, and thus cAMP production, is increased in response to decreased cardiac function in heart failure.

For many decades, it was believed that the major target of cAMP signaling is PKA and that the PKA-mediated increase in myocyte contractility is the only mechanism compensating for cardiac dysfunction in heart failure. Recently, however, exchange protein activated by cAMP (Epac) was identified as a new target of cAMP signaling that is activated independently of PKA $[4,5]$. Epac has two isoforms (Epac1 and Epac2), and Epac1 is expressed dominantly in the heart [4]. Although the exact role of 
these molecules in regulating cardiac function is not fully understood, Epac has been shown to regulate various cellular functions, such as migration, proliferation, skeletal and masseter muscle hypertrophy, cardiac function, exocytosis or cell apoptosis, via regulation of Rap1, a small GTPase [4-11]. In cardiac myocytes, pharmacological activation of Epac induces myocyte hypertrophy $[12,13]$.

Increased production of cytokines, especially inflammatory cytokines such as tumor necrosis factor alpha (TNF $\alpha$ ), interleukin-1 (IL-1) or IL-6, is responsible, at least in part, for cardiac dysfunction in patients with heart failure [14]. These inflammatory cytokines also play a role in septic shock, which is induced by exposure to bacterial endotoxin, leading to overproduction of these cytokines [15]. Cytokine-induced inducible nitric oxide synthase (iNOS) activation has been reported to play an important role in the development of septic cardiomyopathy $[16,17]$. Septic cardiomyopathy is a well-described complication of severe sepsis, with more than two-thirds of patients exhibiting cardiac dysfunction after the onset of septic shock, even with a concomitant increase in sympathetic nerve activity $[18,19]$. Interestingly, it is also known that the recovery of cardiac function is rapid and near-complete in septic shock, despite the severity of cardiac dysfunction, implying that activation of cAMP/Epac signaling may not merely increase cardiac contractility.

Activation of cytokine receptors is linked to the janus kinase-signal transducer and activator of transcription (Jak-STAT) pathway, which is a major intracellular signaling pathway [20]. Suppressor of cytokine signaling-3 (SOCS3) protein is induced upon cytokine receptor activation through STAT-dependent elements in the promoter. SOCS3 exerts negative feedback effects on cytokine signaling via the Jak-STAT pathway [21]. To date, interaction between the sympathetic nervous system and pro-inflammatory cytokine signaling remains poorly understood, despite the fact that both play an important role in the development of heart failure.

Recent studies have demonstrated that Epac regulates cytokine signaling in macrophages and endothelial cells [22-24]. We thus hypothesized that a novel cAMP/Epac signaling mechanism regulates cardiac function in heart failure, working independently of the PKA-mediated enforcement of cardiac contractility. In the study reported here, we show that activation of the cAMP/Epac pathway protects the cardiac myocytes against cytokine-induced dysfunction, most likely through inhibition of the JakSTAT pathway via SOCS3, with subsequent changes in iNOS expression. These results suggest that Epac plays a key role in pro-inflammatory cytokine-induced cardiac dysfunction.

\section{Materials and methods}

\section{Reagents}

All chemicals were purchased from Sigma (St. Louis, MO), except for 8-(4-chlorophenylthio)-2'-O-Me-cAMP-AM (8CPT-AM), which was purchased from Biolog Life Science Institute (Bremen, Germany).

\section{Myocyte preparation}

Primary cultures of neonatal rat cardiac myocytes and adult rat ventricular myocytes were prepared as described in our previous publications [24, 25].

\section{Immunoblotting}

Immunoblotting was conducted using commercially available antibodies. Signal transducer and activator of transcription 1 (STAT1), STAT3, phosphor-STAT1 (Tyr701) and phosphor-STAT3 (Tyr705) antibodies were purchased from Cell Signaling Technology (Danvers, MA). iNOS and SOCS3 antibodies were purchased from Immuno-Biological Laboratories Inc. (Minneapolis, MN) and Cayman Chemical (Ann Arbor, MI), respectively. Protein expression was quantified by densitometry.

\section{Real-time quantitative PCR}

Total RNA was extracted using TRIzol Reagent (Invitrogen, Thermo Fisher Scientific, Carlsbad, CA ) according to the manufacturer's protocol. Total RNA was reverse-transcribed with the SuperScript First-Strand Synthesis System for RT-PCR kit (Invitrogen) according to the manufacturer's instructions.

mRNA expression of SOCS3 and SOCS1 was quantified by quantitative real-time PCR using the ABI-PRISM ${ }^{\circledR} 7700$ sequence detection system (Applied Biosystems, Thermo Fisher Scientific, Foster City, CA) with the SYBR Green PCR Master Mix. The primer pairs for SOCS3 and SOC1 were: SOCS3 (forward, 5'-CTGGACCCATTCGGGAGTTC-3'; reverse, $5^{\prime}$-AACTGGGAGCTACCGACCATTG- $3^{\prime}$ ) and SOCS1 (forward, 5'-CTGCGGCTTCTATTGGGGAC-3'; reverse, $5^{\prime}$-AAAAGGCAGTCGAAGGTCTCG-3'). The relative amount of mRNA of SOCS3 and SOCS1 was normalized to $18 \mathrm{~S}$ rRNA.

\section{Measurements of intracellular $\mathrm{Ca}^{2+}$ concentration and myocyte shortening}

Freshly isolated adult rat myocytes were placed on a laminin-coated 3-cm dish and incubated with or without 
8-CPT-AM $(10 \mu \mathrm{mol} / \mathrm{L})$ for $5 \mathrm{~h}$ in medium at $37{ }^{\circ} \mathrm{C}$ before dye loading or measurement of myocyte shortening.

Myocytes were loaded together with the fluorescent indicator fura-2 acetoxymethyl ester (fura-2 AM; Molecular Probes, Thermo Fisher Scientific, Eugene, OR) as described previously, with some modifications [26]. In brief, $5 \mu \mathrm{L}$ of a $1 \mathrm{mmol} / \mathrm{M}$ stock solution of fura- $2 \mathrm{AM}$ (dissolved in dimethyl sulfoxide) was added to cells in $2.0 \mathrm{ml}$ Tyrode solution (in mM: HEPES, 5; $\mathrm{NaCl}, 140$; $\mathrm{KCl}, 5 ; \mathrm{MgCl}_{2}, 1$; glucose, $10 ; \mathrm{CaCl}_{2}, 1.8 ; \mathrm{pH}$ adjusted to 7.4 with $\mathrm{NaOH})$ to give a final fura-2 concentration of $5 \mu \mathrm{mol} / \mathrm{L}$. Cells were loaded for $20 \mathrm{~min}$ at room temperature, then washed in Tyrode solution twice to remove unincorporated fura-2 $\mathrm{AM}$ and incubated with or without the addition of IL-6 $(30 \mathrm{ng} / \mathrm{ml})$ for $30 \mathrm{~min}$ at room temperature before the response of intracellular $\mathrm{Ca}^{2+}$ to isoproterenol (ISO) was measured.

Conversion of fura-2 fluorescence ratio to intracellular $\mathrm{Ca}^{2+}$ concentration was performed as described previously, with some modifications [27, 28]. In brief, the fura-2-loaded cells were placed on the stage of an inverted microscope (Nikon Eclipse TE2000; Nikon Corp., Tokyo, Japan). To measure intracellular $\mathrm{Ca}^{2+}$ concentration, we alternatively illuminated myocytes with 340- and 380-nm light using a high-speed wavelength-switching device (Lambda SC; Shutter Instruments Co., Novato, CA), and images were recorded with an electron-multiplying chargecoupled device camera (Evolve 512; Photometrics, Tucson, AZ). The images were analyzed using image analysis software (NIS-Elements 3.1; Nikon Corp.). Regions of interest (ROIs) were selected in isolated adult rat myocytes, and fluorescence signals were monitored in the created ROIs in the presence or absence of 8-CPT-AM $(10 \mu \mathrm{mol} /$ L) for $30 \mathrm{~s}$ at baseline [29]. The ISO-induced elevation of the fluorescence signal was then monitored at increasing $\mathrm{Ca}^{2+}$ concentrations $\left(10^{-7}, 10^{-6}\right.$ and $\left.10^{-5} \mathrm{M}\right)$ in the presence of ISO for $30 \mathrm{~s}$. Mean fluorescence signals were converted to free $\mathrm{Ca}^{2+}$ concentration by accessing NISElement ratio dialogs.

Measurements of myocyte shortening in response to ISO were performed as described previously with or without the addition of IL-6 $(30 \mathrm{ng} / \mathrm{ml})$ for $30 \mathrm{~min}$ at room temperature before the measurements [30].

\section{Statistical analysis}

All data were presented as mean \pm standard error of the mean. Data were compared using Student's $t$ test when two samples were considered or using analysis of variance followed by Bonferroni posttest for three or more samples. Differences were considered to be significant at $p<0.05$.

\section{Results}

\section{Effects of various cytokines on the Jak-STAT pathway in cardiac myocytes}

Lipopolysaccharide injection is known to increase the serum levels of cytokines, such as IL-1 $\beta$, IL-6, IL-10, IL-17, interferon gamma (IFN- $\gamma$ ), KC (keratinocyte-derived chemokine), MCP-1 (monocyte chemotactic protein-1), RANTES (regulated upon activation, normal T cell expressed and secreted) and TNF- $\alpha$, and thereby augments tyrosine phosphorylation of STAT3 in the liver and kidneys [31, 32]. However, the contribution of these cytokines to STAT phosphorylation in the heart has not been well studied. We first examined to what extent each cytokine contributed to the phosphorylation of STAT in neonatal rat cardiac myocytes. Phyosphorylation of STAT3 at Tyrosine 705 (Tyr705) was significantly and strikingly increased in response to IL-6 (14-fold) (Fig. 1a), but not to other cytokines, with phosphorylation peaking at $30 \mathrm{~min}$ after treatment with IL-6 (Fig. 1c). Phosphorylation of STAT1 at Tyrosine 701 (Tyr701) was significantly increased in response to IL-6 (2fold) and IFN- $\gamma$ (13-fold), but not to other cytokines (Fig. 1b), and IL-6-mediated phosphorylation of STAT1 also peaked at $30 \mathrm{~min}$ (Fig. 1d). Thus, among the various cytokines examined, our results show that IL-6 may play an important role in the activation of the Jak-STAT pathway, a major cytokine signaling pathway, in the heart.

\section{Effects of Epac on activation of the Jak-STAT pathway in response to IL-6}

Epac1 has recently been shown to modulate cytokine signaling in non-cardiac cells, such as macrophages or endothelial cells, in vitro [22, 23, 33]. We thus examined the consequences of Epac activation on IL-6 signaling, as shown above, on cardiac myocytes. IL-6-stimulated phosphorylation of STAT3 and STAT1 was examined after treatment of the cells with 8-CPT-AM, an Epac-selective cAMP analog [34]. While 8-CPT-AM $(10 \mu \mathrm{mol} / \mathrm{L})$ had no effect on basal phosphorylation of STAT3 or STAT1 in neonatal rat cardiac myocytes, pretreatment with 8-CPTAM for $5 \mathrm{~h}$ significantly diminished the IL-6-induced phosphorylation of STAT3 (Fig. 2a) and STAT1 (Fig. 2b). Thus, pharmacological activation of Epac did not alter basal phosphorylation, but it did potently inhibit IL-6-induced STAT phosphorylation. On the other hand, in the presence of Epac1 selective inhibitor CE3F4 $(10 \mu \mathrm{mol} / \mathrm{L})$, IL-6-induced STAT3 phosphorylation was significantly enhanced (Fig. 2c), suggesting that endogenous Epac1 inhibits IL-6-induced STAT3 phosphorylation. 

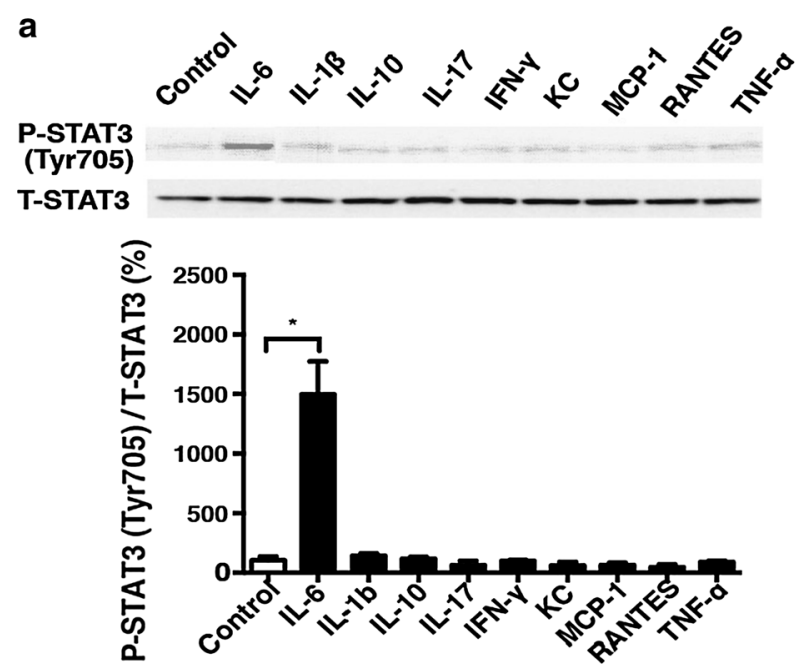

c
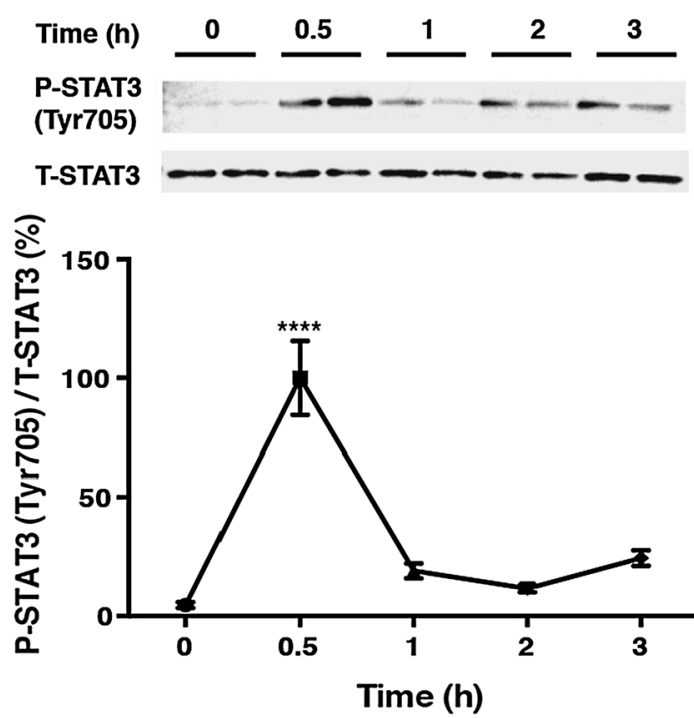

Fig. 1 Effects of various cytokines on signal transducer and activator of transcription (STAT) phosphorylation and the time course of interleukin (IL)-6-mediated STAT phosphorylation. a Phosphorylation of signal transducer and activator of transcription 3 (STAT3) at Tyrosine 705 (Tyr705) was examined at $30 \mathrm{~min}$ after treatment with IL-6 (30 ng/ml), IL-1 $\beta$ (10 ng/ml), IL-10 (10 ng/ml), IL-17 (10 ng/ $\mathrm{ml})$, interferon gamma $(I F N-\gamma ; 10 \mathrm{ng} / \mathrm{ml})$, keratinocyte-derived chemokine $(K C ; 50 \mathrm{ng} / \mathrm{ml})$, monocyte chemotactic protein-1 (MCP$1 ; 10 \mathrm{ng} / \mathrm{ml}$ ), RANTES (regulated upon activation, normal $\mathrm{T}$ cell expressed and secreted; $10 \mathrm{ng} / \mathrm{ml}$ ), and tumor necrosis factor alpha $(T N F-\alpha ; 10 \mathrm{ng} / \mathrm{ml})$. The phosphorylation was upregulated by 14 -fold in response to IL-6 $(n=4$, *significantly different at $p<0.05$, Student's $t$ test). T-STAT Total STAT, P-STAT phosphorylated STAT. b Phosphorylation of signal transducer and activator of transcription 1 (STAT1) at Tyrosine $701($ Tyr 701$)$ was examined at $30 \mathrm{~min}$ after

\section{Epac activation increased SOCS3 and SOCS1 levels}

Among the negative regulators of the Jak-STAT pathway, we found that the mRNA expression of SOCS3 and SOCS1 was increased by Epac activation (Fig. 3). SOCS3 mRNA expression was significantly increased at $1 \mathrm{~h}$ after 8-CPT-

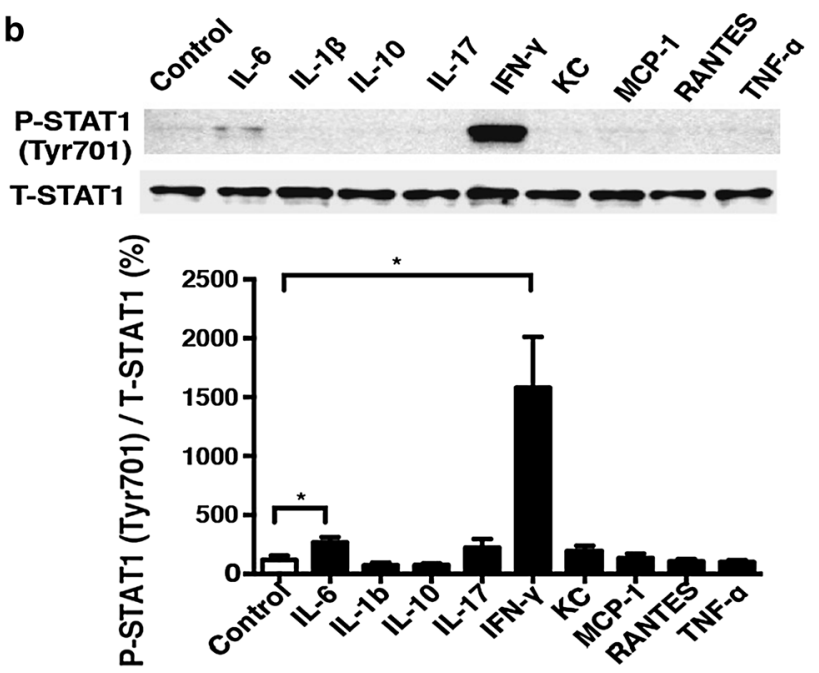

d

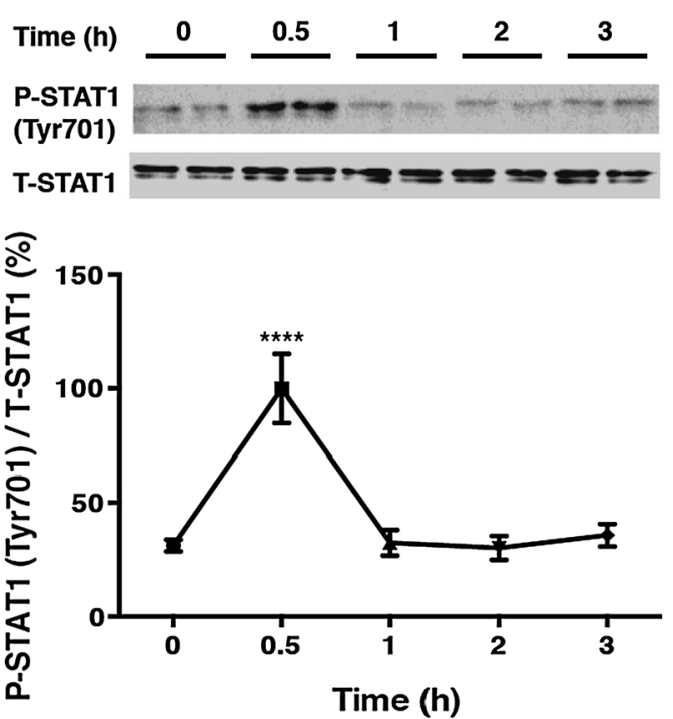

treatment with IL-6 (30 ng/ml), IL-1 $\beta(10 \mathrm{ng} / \mathrm{ml}), \mathrm{IL}-10(10 \mathrm{ng} / \mathrm{ml})$, IL-17 (10 ng/ml), IFN- $\gamma(10 \mathrm{ng} / \mathrm{ml}), \mathrm{KC}(50 \mathrm{ng} / \mathrm{ml}), \mathrm{MCP}-1$ (10 ng/ $\mathrm{ml})$, RANTES $(10 \mathrm{ng} / \mathrm{ml})$ and TNF- $\alpha(10 \mathrm{ng} / \mathrm{ml})$. The phosphorylation was upregulated by 13 -fold in response to IFN- $\gamma$ and by 2 -fold in response to IL-6 $(n=4, *$ significantly different at $p<0.05$, Student's $t$ test). c Time course of IL-6 (30 ng/ml)-mediated STAT3 phosphorylation at Tyr705. Phosphorylation peaked at $30 \mathrm{~min}$ after treatment with IL-6 $(30 \mathrm{ng} / \mathrm{ml})$ and then decreased gradually $[n=4$, ****significantly different at $p<0.0001$ vs. $0 \mathrm{~h}$, one-way analysis of variance (ANOVA)]. d Time course of IL-6 $(30 \mathrm{ng} / \mathrm{ml})$-mediated phosphorylation of STAT1 at Tyr701. Phosphorylation peaked at 30 min after treatment with IL-6 and then decreased gradually ( $n=4-6, * * * *$ significantly different at $p<0.0001$ vs. $0 \mathrm{~h}$, one-way ANOVA). Data are presented as the mean \pm standard error of the mean (SEM)

AM treatment $(10 \mu \mathrm{mol} / \mathrm{L})$ by 1.7 -fold $(p<0.05, n=4)$ (Fig. 3a), and SOCS1 mRNA expression was significantly increased at $3 \mathrm{~h}$ after 8 -CPT-AM treatment (Fig. 3b) by 6.2 -fold $(p<0.01, n=3-4)$. These data suggest that Epac activation induces mRNA expression of SOCS3 and SOCS1 and that these molecules may function as negative 

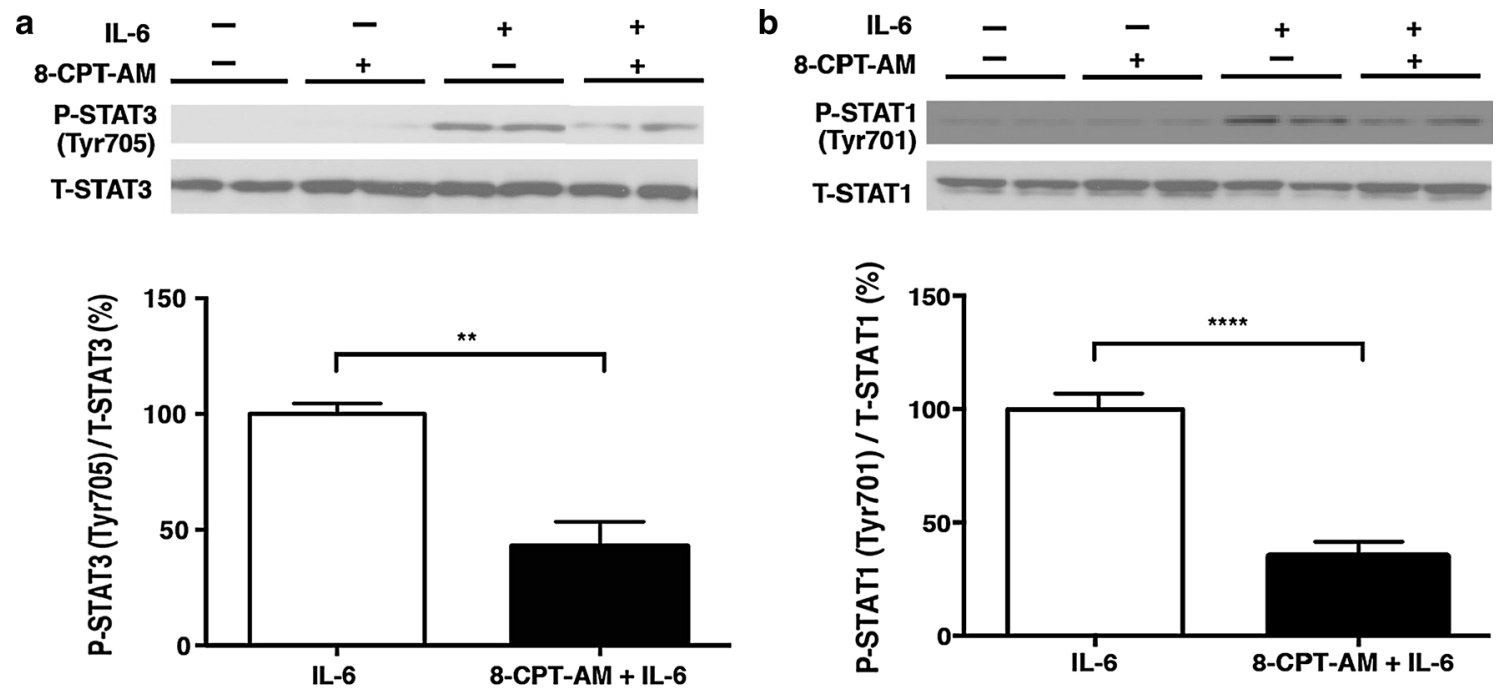

C

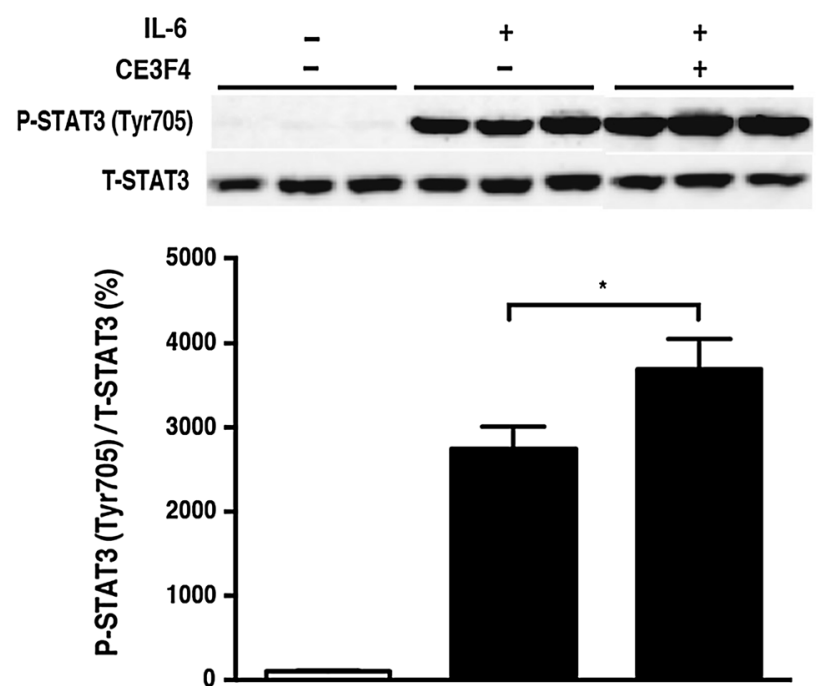

Fig. 2 Effects of exchange protein activated by cAMP (Epac) on the activation of the Janus kinase-signal transducers and activators of transcription (Jak-STAT) pathway in response to IL-6. a, b Pretreatment of neonatal rat cardiac myocytes with 8-(4-chlorophenylthio)- $2^{\prime}$ $O$-Me-cAMP-AM $(8-C P T-A M ; 10 \mu \mathrm{mol} / \mathrm{L})$ for $5 \mathrm{~h}$ significantly reduced both IL-6-mediated phosphorylation of STAT3 at Tyr705 by $57 \pm 11.5 \%$ (a) $(n=5-6$, **significantly different at $p<0.01$,

regulators of the IL-6-mediated Jak-STAT pathway activation in the 8-CPT-AM-treated cardiac myocytes.

\section{Epac-mediated SOCS3 expression via phospholipase C/protein kinase $\mathrm{C}$}

We next examined the role of phospholipase C (PLC) and protein kinase $\mathrm{C}$ (PKC) in the increase of SOCS3 due to 8-CPT-AM treatment because a recent study indicates that those proteins are involved in cAMP elevation-induced SOCS3 accumulation in COS cells [35]. As expected, these increases were abolished in the presence of the PLC inhibitor
Student's $t$ test) and IL-6-mediated phosphorylation of STAT1 at Tyr701 by $65 \pm 6.8 \%$ (b) $(n=6-8, * * * *$ significantly different at $p<0.0001$, Student's $t$ test). c Pretreatment of neonatal rat cardiac myocytes with Epac1 selective inhibitor CE3F4 for 30 min significantly enhanced IL-6-mediated phosphorylation of STAT3 at Tyr705 by $35 \pm 13.0 \%$ ( $n=6$, *significantly different at $p<0.05$, one-way ANOVA). Data are presented as the mean \pm SEM

U73122 (Fig. 4a) or PKC inhibitor Ro-31-7549 (Fig. 4b), suggesting that Epac activation increased SOCS3 expression via PLC/PKC mediation. Taken together, these results led us to hypothesize that Epac increases SOCS3- and inhibits IL6-mediated phosphorylation of STAT in cardiac myocytes.

\section{Effects of Epac activation on IL-6-induced iNOS expression in cardiac myocytes}

To address the functional consequence of Epac-mediated regulation of IL-6 signaling, we examined changes in molecules whose expression may be directly regulated by 


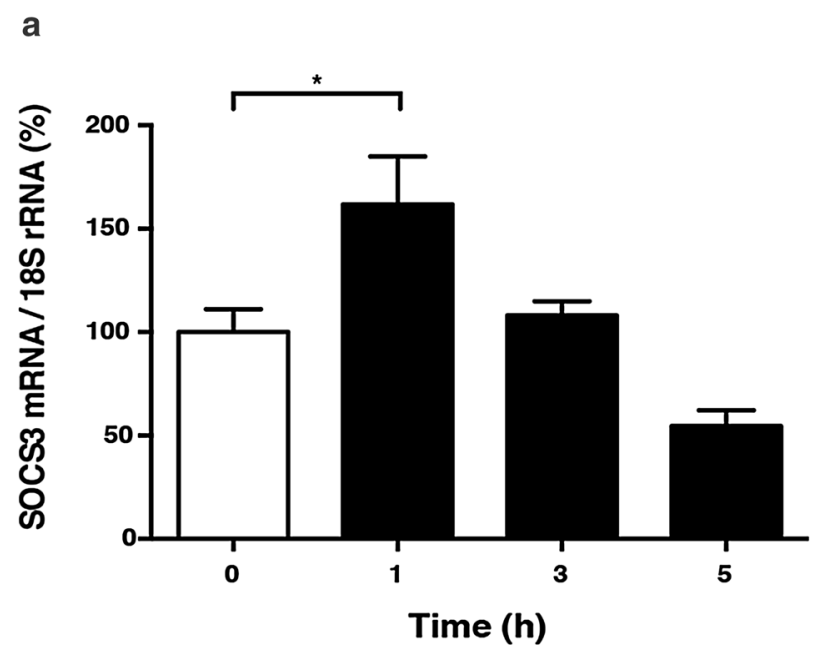

Fig. 3 Time course of Epac-mediated expression of suppressor of cytokine signaling-3 and -1 (SOCS3, SOCS1, respectively) in cardiac myocytes. a, b mRNA expression of SOCS3 (a) and SOCS1 (b) was examined by quantitative real-time PCR in neonatal rat cardiac myocytes in the presence of 8 -CPT-AM $(10 \mu \mathrm{mol} / \mathrm{L})$ for the indicated time. mRNA expression of SOCS3 and SOCS1 gradually increased with 8-CPT-AM treatment. a SOCS3 mRNA expression peaked at a

IL-6/Jak/STAT and which also play an important role in regulating cardiac function. We found that iNOS protein expression was increased by IL-6 $(30 \mathrm{ng} / \mathrm{ml})$ in a timedependent manner, with a maximal increase of 4.5 -fold at $6 \mathrm{~h}$ after IL-6 treatment (Fig. 4c), but that this increase was significantly inhibited by a 5 -h pretreatment with 8-CPTAM $(10 \mu \mathrm{mol} / \mathrm{L})$. These results led us to conclude that pharmacological activation of Epac inhibited the expression of iNOS.

\section{Effects of Epac on $\mathrm{Ca}^{2+}$ regulation and cell shortening in cardiac myocytes}

Cardiac contraction and relaxation are influenced by the intracellular increase in $\mathrm{Ca}^{2+}$ during systole and its decrease during diastole. $\mathrm{Ca}^{2+}$ uptake by the sarcoplasmic reticulum is regulated via phospholamban phosphorylation and its release is regulated via the ryanodine receptor. We previously demonstrated that the basal and peak intracellular $\mathrm{Ca}^{2+}$ concentration is significantly decreased in isolated cardiac myocytes of Epac1-null mice compared with wild-type controls, with reduced phospholamban phosphorylation at the serine 16 residue [7]. In that same study, we also demonstrated that silencing Epac1 in cardiac myocytes attenuated ISO-mediated increases in phosphorylation of the ryanodine receptor on the serine 2808 and serine 2814 residues [7]. These data suggest that Epac1 activation, on its own, can cause changes in $\mathrm{Ca}^{2+}$ signaling and contractility in isolated cardiac myocytes.

IL-6 has been shown to decrease the intracellular $\mathrm{Ca}^{2+}$ concentration and cell contraction in cultured chick cardiac

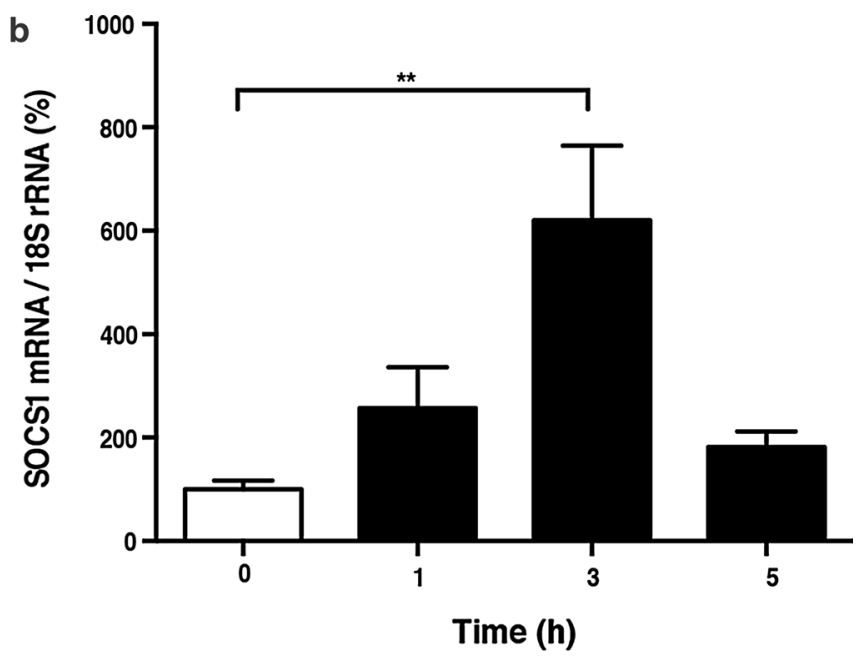

significant increase of 1.7 -fold at $1 \mathrm{~h}$ after 8 -CPT-AM treatment ( $n=4$, *significantly different at $p<0.05$ vs. baseline, one-way ANOVA). b SOCS1 mRNA expression peaked at a significant increase of 6.2 -fold at $3 \mathrm{~h}$ after 8-CPT-AM treatment $(n=3-4$, **significantly different at $p<0.01$ vs. baseline, one-way ANOVA). $N S$ Not significant. Data are presented as the mean \pm SEM

myocytes through the induction of iNOS [36]. Our findings suggest that Epac can increase SOCS3 and SOCS1 expression, leading to inhibition of STAT3 phosphorylation and, consequently, iNOS expression. Consequently, it is possible that Epac antagonizes IL-6 with respect to regulation of the $\mathrm{Ca}^{2+}$ concentration and thus cell contraction. In our study, ISO increased the intracellular $\mathrm{Ca}^{2+}$ concentration in a dose-dependent manner in adult rat cardiac myocytes. This increase was significantly attenuated when the cells were pretreated with IL-6 $(30 \mathrm{ng} / \mathrm{ml})$ for $6 \mathrm{~h}$, as expected (Fig. 5a). However, pretreatment with 8-CPT-AM $(10 \mu \mathrm{mol} / \mathrm{L})$ for $5 \mathrm{~h}$ abolished this attenuation by IL-6 (Fig. 5 b). When myocyte shortening was examined as an index of cardiac contractility, ISO $\left(10^{-5} \mathrm{~mol} / \mathrm{L}\right)$ significantly increased cell shortening, and this increase was significantly attenuated by IL- $6(30 \mathrm{ng} / \mathrm{ml})$ pretreatment for $6 \mathrm{~h}$ (Fig. 5c). Importantly, pretreatment with 8-CPT-AM for $5 \mathrm{~h}$ abolished this attenuation with IL-6 (Fig. 5d). Taken together, these findings suggest that pharmacological activation of Epac plays a key role in antagonizing IL-6, resulting in preservation of the $\mathrm{Ca}^{2+}$ regulation and thus preservation of cardiac contractility, at least in cultured myocytes.

\section{Discussion}

Interleukin-6 inhibited the increase in intracellular $\mathrm{Ca}^{2+}$ concentration and thereby also myocyte shortening stimulated by ISO. This effect of IL-6 was diminished by pharmacological activation of Epac in cardiac myocytes, 
a

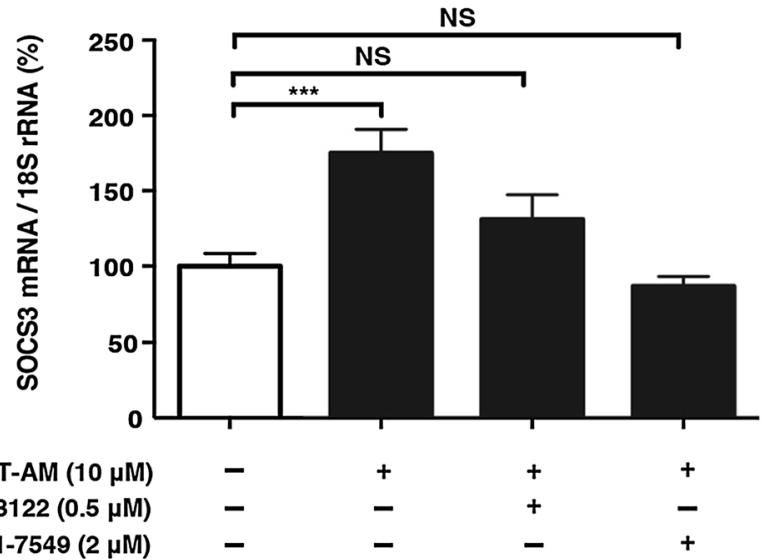

b

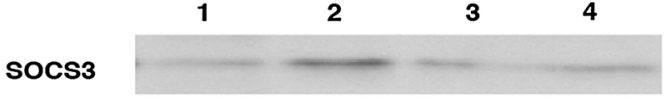

GAPDH

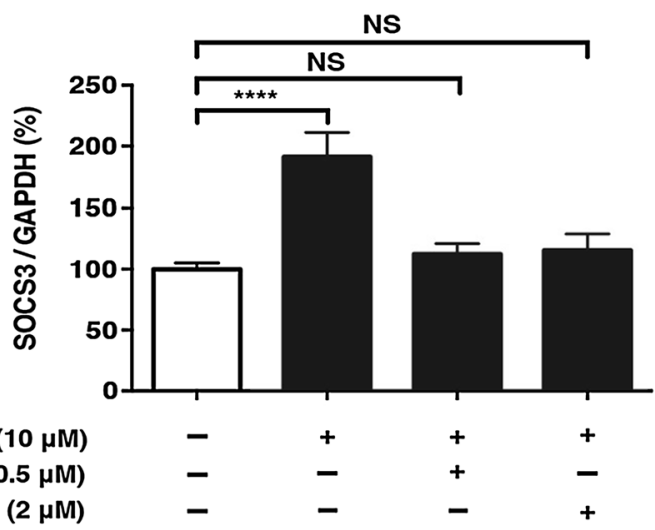

C

IL-6

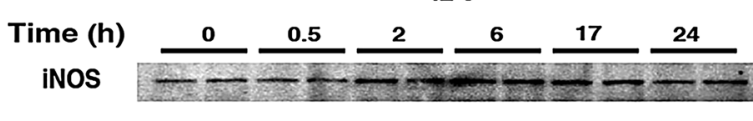

8-CPT-AM + IL-6

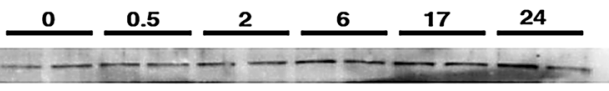

GAPDH

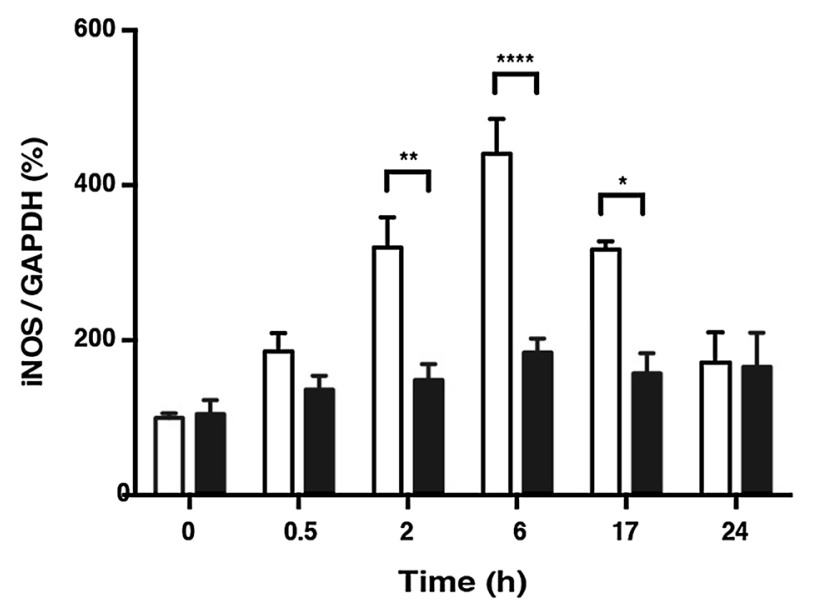

Fig. 4 Effects of Epac activation on SOCS3 expression and IL-6 induced inducible nitric oxide synthase $(i N O S)$ expression in cardiac myocytes. a SOCS3 mRNA expression, examined by quantitative real-time PCR in neonatal rat cardiac myocytes in the presence of 8-CPT-AM $(10 \mu \mathrm{mol} / \mathrm{L})$ for $1 \mathrm{~h}$, was significantly increased by 1.8 fold. However, Epac-mediated SOCS3 upregulation was blunted by the addition of a phospholipase C (PLC) inhibitor (U73122, $0.5 \mu \mathrm{mol} /$ $\mathrm{L})$ or protein kinase $\mathrm{C}(\mathrm{PKC})$ inhibitor $($ Ro-31-7549, $2 \mu \mathrm{mol} / \mathrm{L})$ ( $n=6-10, * * *$ significantly different at $p<0.001$ vs. baseline, oneway ANOVA). b SOCS3 protein expression, examined by western blotting in the presence of 8 -CPT-AM $(10 \mu \mathrm{mol} / \mathrm{L})$ for $5 \mathrm{~h}$, was

most likely through SOCS3/STAT/iNOS signaling. It has long been believed that the major target of catecholamine/ cAMP signaling is PKA and that the PKA-mediated significantly increased by 2.2 -fold in the presence of 8-CPT-AM. This upregulation was also blunted by the addition of PLC inhibitor or PKC inhibitor ( $n=6-11, * * * *$ significantly different at $p<0.0001$ vs. baseline, one-way ANOVA). c Western blot analysis of iNOS expression in neonatal rat cardiac myocytes treated for the indicated times with IL-6 $(30 \mathrm{ng} / \mathrm{ml})$. iNOS expression increased gradually, peaking at $6 \mathrm{~h}$. However, pretreatment with 8 -CPT-AM $(10 \mu \mathrm{mol} / \mathrm{L})$ for $5 \mathrm{~h}$ inhibited the IL-6-mediated increase of iNOS protein expression $(n=4-7$, *significantly different at $p<0.05$, two-way ANOVA). GAPDH Glyceraldehyde 3-phosphate dehydrogenase. Data are presented as the mean \pm SEM

increase in myocyte contractility is the only mechanism compensating for cardiac dysfunction in heart failure. However, our findings suggest that there is another 


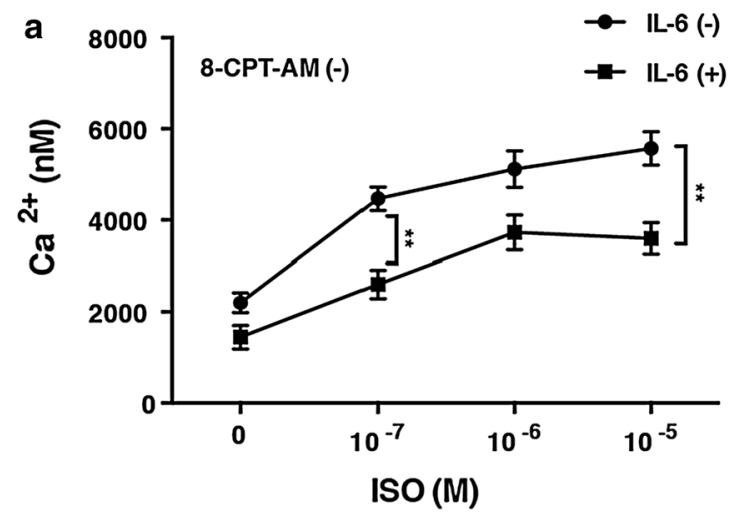

C

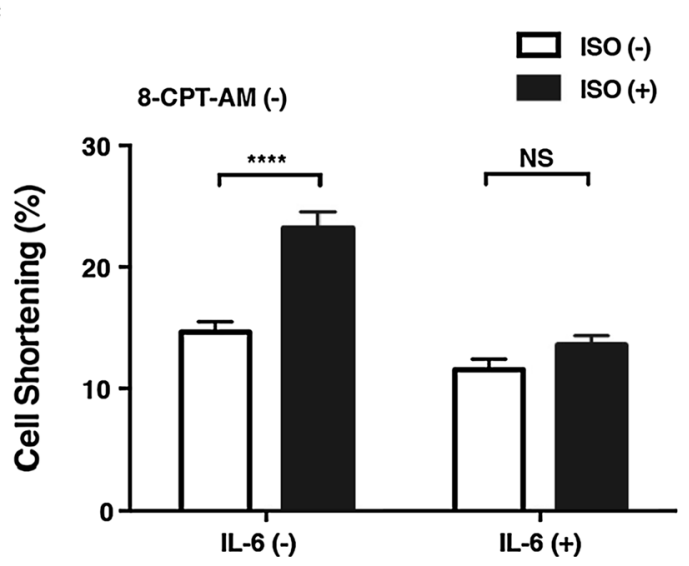

Fig. 5 Effects of Epac activation on $\mathrm{Ca}^{2+}$ concentration $(\mathbf{a}, \mathbf{b})$ and contractility of cardiac myocytes $(\mathbf{c}, \mathbf{d})$. a Intracellular $\mathrm{Ca}^{2+}$ concentration in response to increasing concentrations of isoproterenol $\left(I S O ; 0-10^{-5} \mathrm{~mol} / \mathrm{L}\right)$ in adult rat cardiac myocytes with or without a 6-h IL-6 $(30 \mathrm{ng} / \mathrm{ml})$ pretreatment. b The effect of a $5-\mathrm{h}$ 8 -CPT-AM $(10 \mu \mathrm{mol} / \mathrm{L})$ pretreatment on the ISO-induced increase of $\mathrm{Ca}^{2+}$. Pretreatment with 8-CPT-AM restored the increase of $\mathrm{Ca}^{2+}$

mechanism that involves Epac and that this mechanism may be able to restore cardiac myocyte function, at least in the context of cytokine-induced dysfunction. Thus, Epac appears to play an important role, unlike PKA, in the crosstalk between the sympathetic nervous system and proinflammatory cytokine signaling in the development of heart failure.

Of the various cytokines examined in our study, we found that IL-6 was the most prominent activator of STAT3 in cardiac myocytes and that IL-6-mediated STAT3 activation reduced the ISO-induced increase in $\mathrm{Ca}^{2+}$ concentration and cardiac contractility through the induction of iNOS. We also demonstrated that IL-6 significantly increased the phosphorylation of STAT1 even though IFN- $\gamma$ is the most prominent activator of STAT1 in cardiac myocytes. Also, IL-6-mediated STAT1 activation was significantly decreased by the activation of Epac in cardiac myocytes. Previous studies have shown that STAT1 phosphorylation may be able to induce iNOS expression with the activation of p44/42 mitogen-activated
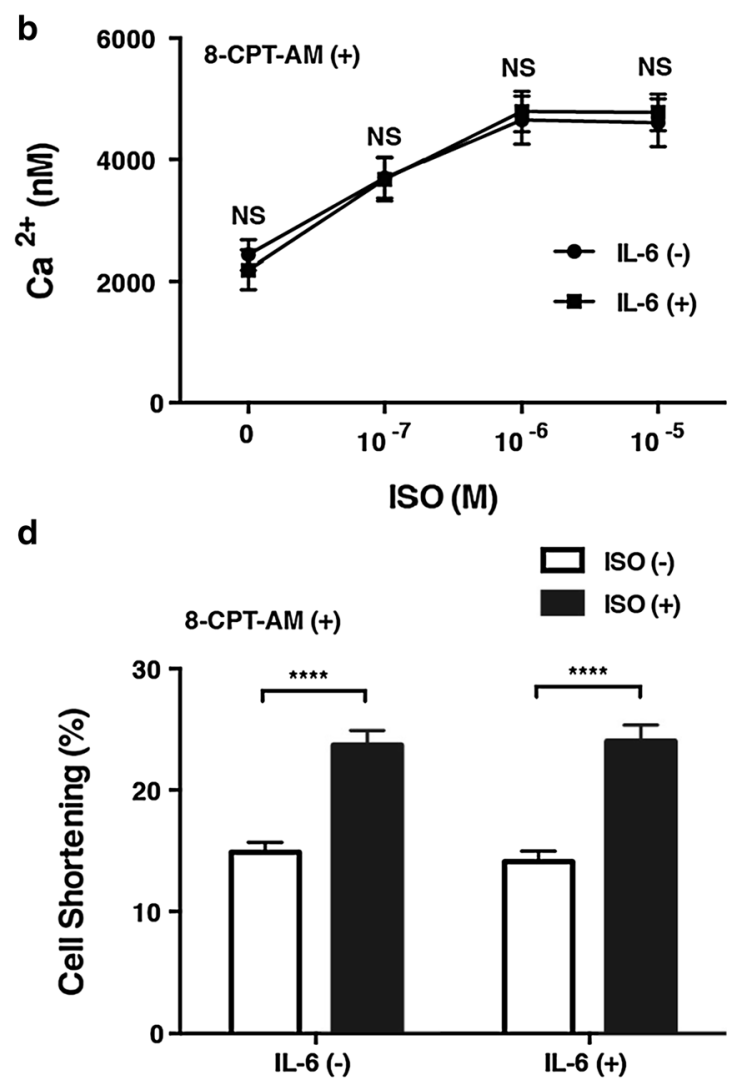

transients suppressed by IL-6 $(n=29-64$, **significantly different at $p<0.01$, two-way ANOVA). c Cardiac cell shortening at baseline and in response to ISO $\left(10^{-5} \mathrm{~mol} / \mathrm{L}\right)$. d Pretreatment with 8-CPT-AM $(10 \mu \mathrm{M})$ restored cell shortening suppressed by IL-6 $(30 \mathrm{ng} / \mathrm{ml})$ ( $n=24-31, * * * *$ significantly different at $p<0.0001$, two-way ANOVA). Data are presented as the mean \pm SEM

protein kinase in cardiac myocytes [37]. Taken together, these results suggest that cytokine-mediated cardiac dysfunction is most likely mediated by nitric oxide production $[14,38]$. We also found that this deterioration can be ameliorated by Epac activation. Cytokine levels are increased in patients with chronic congestive heart failure [14], in whom sympathetic nerve activity is also increased, suggesting that Epac activation may be beneficial in such patients, in addition to those with septic heart failure.

Our observation of an increase in SOCS3 mRNA/protein levels in cardiac myocytes in response to Epac activation is consistent with previous findings. For example, elevated cAMP levels have been found to promote SOCS3 accumulation in cultured cell lines, such as mouse embryonic fibroblasts or COS cells [22, 35, 39], most likely through the PLC/PKC pathway, as demonstrated in COS cells [35]. We also confirmed the increase in SOCS1 mRNA level in cardiac myocytes in response to Epac activation, which is known to exert negative feedback effects on cytokine signaling via the Jak-STAT pathway [40, 41]. More 
importantly, SOCS1-deficient mice are sensitive to LPSinduced lethal effects than wild-type control mice [42]. In our study, however, we demonstrated the functional significance of such changes, i.e., that Epac increased mRNA expression of SOCS3 and SOCS1 in cultured cardiac myocytes, thereby inhibiting IL-6/STAT/iNOS signaling and protecting the cardiac myocytes against cytokine-induced dysfunction.

Our findings suggest that the beneficial effect of the sympathetic nervous system involves not only enhancement of cardiac contractility through the classic cAMP/ PKA pathway, but also inhibition of the Jak/STAT pathway via the newly described cAMP/Epac pathway. Epac signaling can attenuate pro-inflammatory cytokine-induced Jak/STAT signaling via SOCS3 and SOCS1, leading to the downregulation of iNOS, which is associated with cardiac dysfunction. It is known that cardiac dysfunction in sepsis is severe but that it may be restored almost completely in many cases $[18,19]$. In cardiac myocytes, IL-6 treatment increases phosphorylation of STAT3 at the Tyr705 through the enhanced de novo synthesis of iNOS protein, leading to increased NO production and decreased cardiac contractility [38]. Furthermore, both IL-6-mediated STAT3 phosphorylation at Tyr705 and iNOS expression are blocked by AG490, a Jak2 inhibitor, or by genistein, a protein tyrosine kinase inhibitor, in cardiac myocytes [38]. IL-6 treatment also inhibits the ISO-induced increase in $\mathrm{Ca}^{2+}$ level and decreases cell contraction in cardiac myocytes [36]. However, pretreatment with $N^{\mathrm{G}}$-monomethyl-Larginine, an analog of L-arginine and a potent inhibitor of NO production, inhibits the IL-6-mediated decrease in intracellular $\mathrm{Ca}^{2+}$ transient and cell contraction in cardiac myocytes [36]. These previous data, together with the data from our study, indicate the causal relationship and functional significance of such changes, i.e., that Epac increased the expression of SOCS3 and SOCS1 in our cultured cardiac myocytes, thereby inhibiting IL-6/STAT/ iNOS signaling and protecting the cardiac myocytes against cytokine-induced dysfunction.

Epac activation has been reported to increase myofilament $\mathrm{Ca}^{2+}$ sensitivity of isometric force through the increased phosphorylation of two key sarcomeric proteins, namely, cardiac myosin binding protein- $\mathrm{C}$ and cardiac troponin I [43], and it might also contribute to the Epacmediated compensation of cardiac dysfunction in sepsis. We speculate that cAMP/Epac-mediated cardiac protection, as opposed to the cardiac damage caused by cytokines/endotoxin, may explain this beneficial effect, at least in part. Thus, we consider that the sympathetic nervous system can regulate cardiac function through multiple mechanisms.

In summary, we have demonstrated that Epac-mediated SOCS3 and SOCS1 expression protects the heart against cytokine-mediated cardiac dysfunction by inhibiting STAT3 phosphorylation and subsequent iNOS production. Our findings also suggest that Epac1 and its downstream pathway, including Jak2 or STAT3, may be an attractive target for treatment of cardiac failure in sepsis, and possibly cardiac failure in general, since cytokine-induced cardiac dysfunction plays an important role in the pathogenesis of cardiac failure [21].

Acknowledgements This study was supported in part by the Japan Society for the Promotion of Science (JSPS) KAKENHI Grant (25460296, 16K08501 to TF, 23591087 to SO, 16H05300, 16K15205 to YI); The Ministry of Education, Culture, Sports, Science and Technology (MEXT) KAKENHI Grant (22136009 to YI); the MEXT-Supported Program for the Strategic Research Foundation at Private Universities (S1511018 to SO); the Japan Agency for Medical Research and Development (AMED) (66890005, 66890011, 66890001, 66890023 to YI); a Grant for Strategic Research Promotion of Yokohama City University (S2501 to TF, SO); the Naito Foundation (SO); Senshin Medical Research Foundation (SO); an Academic Contribution from Pfizer Japan (SO) and the Research Foundation for Community Medicine (SO). We thank Yunzhe Bai, Fumika Kawamata, Ayako Makino and Nozomi Hasegawa for their technical assistance and animal care.

Open Access This article is distributed under the terms of the Creative Commons Attribution 4.0 International License (http://crea tivecommons.org/licenses/by/4.0/), which permits use, duplication, adaptation, distribution and reproduction in any medium or format, as long as you give appropriate credit to the original author(s) and the source, provide a link to the Creative Commons license and indicate if changes were made.

\section{References}

1. Okumura S, Kawabe J, Yatani A, Takagi G, Lee MC, Liu J, Takagi I, Sadoshima J, Vatner DE, Vatner SF, Ishikawa Y (2003) Type 5 adenylyl cyclase disruption alters not only sympathetic but also parasympathetic and calcium-mediated cardiac regulation. Circ Res 93:364-371

2. Okumura S, Takagi G, Kawabe J, Yang G, Lee MC, Hong C, Liu J, Vatner DE, Sadoshima J, Vatner SF, Ishikawa Y (2003) Disruption of type 5 adenylyl cyclase gene preserves cardiac function against pressure overload. Proc Natl Acad Sci USA 100:9986-9990

3. Kamide T, Okumura S, Ghosh S, Shinoda Y, Mototani Y, Ohnuki Y, Jin H, Cai W, Suita K, Sato I, Umemura M, Fujita T, Yokoyama U, Sato M, Furutani K, Kitano H, Ishikawa Y (2015) Oscillation of cAMP and $\mathrm{Ca}^{2+}$ in cardiac myocytes: a systems biology approach. J Physiol Sci 65:195-200

4. Kawasaki H, Springett GM, Mochizuki N, Toki S, Nakaya M, Matsuda M, Housman DE, Graybiel AM (1998) A family of cAMP-binding proteins that directly activate Rap1. Science 282:2275-2279

5. de Rooij J, Zwartkruis FJ, Verheijen MH, Cool RH, Nijman SM, Wittinghofer A, Bos JL (1998) Epac is a Rap1 guanine-nucleotide-exchange factor directly activated by cyclic AMP. Nature 396:474-477

6. Cai W, Fujita T, Hidaka Y, Jin H, Suita K, Prajapati R, Liang C, Umemura M, Yokoyama U, Sato M, Okumura S, Ishikawa Y (2016) Disruption of Epac1 protects the heart from adenylyl cyclase type 5-mediated cardiac dysfunction. Biochem Biophys Res Commun 475:1-7 
7. Okumura S, Fujita T, Cai W, Jin M, Namekata I, Mototani Y, Jin H, Ohnuki Y, Tsuneoka Y, Kurotani R, Suita K, Kawakami Y, Hamaguchi S, Abe T, Kiyonari H, Tsunemastu T, Bai Y, Suzuki S, Hidaka Y, Umemura M, Ichikawa Y, Yokoyama U, Sato M, Ishikawa F, Izumi-Nakaseko $\mathrm{H}$, Adachi-Akahane S, Tanaka H, Ishikawa Y (2014) EPAC1-dependent phospholamban phosphorylation mediates the cardiac response to stresses. J Clin Invest 124:2785-2801

8. Ohnuki Y, Umeki D, Mototani Y, Jin H, Cai W, Shiozawa K, Suita K, Saeki Y, Fujita T, Ishikawa Y, Okumura S (2014) Role of cyclic AMP sensor Epac1 in masseter muscle hypertrophy and myosin heavy chain transition induced by $\beta_{2}$-adrenoceptor stimulation. J Physiol 592:5461-5475

9. Ohnuki Y, Umeki D, Mototani Y, Shiozawa K, Nariyama M, Ito A, Kawamura N, Yagisawa Y, Jin H, Cai W, Suita K, Saeki Y, Fujita T, Ishikawa Y, Okumura S (2016) Role of phosphodiesterase 4 expression in the Epac1 signaling-dependent skeletal muscle hypertrophic action of clenbuterol. Physiol Rep 4:e12791

10. Kato Y, Yokoyama U, Yanai C, Ishige R, Kurotaki D, Umemura M, Fujita T, Kubota T, Okumura S, Sata M, Tamura T, Ishikawa Y (2015) Epac1 deficiency attenuated vascular smooth muscle cell migration and neointimal formation. Arterioscler Thromb Vasc Biol 35:2617-2625

11. Yokoyama U, Minamisawa S, Quan H, Akaike T, Suzuki S, Jin M, Jiao Q, Watanabe M, Otsu K, Iwasaki S, Nishimaki S, Sato M, Ishikawa Y (2008) Prostaglandin $E_{2}$-activated Epac promotes neointimal formation of the rat ductus arteriosus by a process distinct from that of cAMP-dependent protein kinase A. J Biol Chem 283:28702-28709

12. Metrich M, Lucas A, Gastineau M, Samuel JL, Heymes C, Morel E, Lezoualc'h (2008) Epac mediates $\beta$-adrenergic receptor-induced cardiomyocyte hypertrophy. Circ Res 102:959-965

13. Morel E, Marcantoni A, Gastineau M, Birkedal R, Rochais F, Garnier A, Lompré AM, Vandecasteele G, Lezoulc'h F (2005) cAMP-binding protein Epac induces cardiomyocyte hypertrophy. Circ Res 97:1296-1304

14. Finkel MS, Oddis CV, Jacob TD, Watkins SC, Hattler BG, Simmons RL (1992) Negative inotropic effects of cytokines on the heart mediated by nitric oxide. Science 257:387-389

15. Girardin E, Grau GE, Dayer JM, Roux-Lombard P, Lambert PH (1988) Tumor necrosis factor and interleukin-1 in the serum of children with severe infectious purpura. N Engl J Med 319:397-400

16. Tatsumi T, Akashi K, Keira N, Matoba S, Mano A, Shiraishi J, Yamanaka S, Kobara M, Hibino N, Hosokawa S, Asayama J, Fushiki S, Fliss H, Nakagawa M, Matsubara H (2004) Cytokineinduced nitric oxide inhibits mitochondrial energy production and induces myocardial dysfunction in endotoxin-treated rat hearts. J Mol Cell Cardiol 37:775-784

17. Mebazaa A, De Keulenaer GW, Paqueron X, Andries LJ, Ratajczak P, Lanone S, Frelin C, Longrois D, Payen D, Brutsaert DL, Sys SU (2001) Activation of cardiac endothelium as a compensatory component in endotoxin-induced cardiomyopathy: role of endothelin, prostaglandins, and nitric oxide. Circulation 104:3137-3144

18. Chagnon F, Metz CN, Bucala R, Lesur O (2005) Endotoxininduced myocardial dysfunction: effects of macrophage migration inhibitory factor neutralization. Circ Res 96:1095-1102

19. Flierl MA, Rittirsch D, Huber-Lang MS, Sarma JV, Ward PA (2008) Molecular events in the cardiomyopathy of sepsis. Mol Med 14:327-336

20. Barry SP, Townsend PA, Latchman DS, Stephanou A (2007) Role of the JAK-STAT pathway in myocardial injury. Trends Mol Med 13:82-89

21. Yasukawa H, Hoshijima M, Gu Y, Nakamura T, Pradervand S, Hanada Y, Hanakawa Y, Yoshimura A, Ross J Jr, Chien KR (2001) Suppressor of cytokine signaling-3 is a biomechanical stress-inducible gene that suppresses gp130-mediated cardiac myocyte hypertrophy and survival pathways. J Clin Invest 108:1459-1467

22. Woolson HD, Thomson VS, Rutherford C, Yarwood SJ, Palmer TM (2009) Selective inhibition of cytokine-activated extracellular signal-regulated kinase by cyclic AMP via Epac1-dependent induction of suppressor of cytokine signalling-3. Cell Signal 21:1706-1715

23. Sands WA, Woolson HD, Milne GR, Rutherford C, Palmer TM (2006) Exchange protein activated by cyclic AMP (Epac)-mediated induction of suppressor of cytokine signaling 3 (SOCS-3) in vascular endothelial cells. Mol Cell Biol 26:6333-6346

24. Yokoyama U, Patel HH, Lai NC, Aroonsakool N, Roth DM, Insel PA (2008) The cyclic AMP effector Epac integrates pro- and anti-fibrotic signals. Proc Natl Acad Sci USA 105:6386-6391

25. Dodge-Kafka KL, Soughayer J, Pare GC, Carlisle Michel JJ, Langeberg LK, Kapiloff MS, Scott JD (2005) The protein kinase A anchoring protein mAKAP coordinates two integrated cAMP effector pathways. Nature 437:574-578

26. Ardell JL, Rajendran PS, Nier HA, KenKnight BH, Armour JA (2015) Central-peripheral neural network interactions evoked by vagus nerve stimulation: functional consequences on control of cardiac function. Am J Physiol Heart Circ Physiol 309:H1740H1752

27. Kettlewell S, Cabrero P, Nicklin SA, Dow JA, Davies S, Smith GL (2009) Changes of intra-mitochondrial $\mathrm{Ca}^{2+}$ in adult ventricular cardiomyocytes examined using a novel fluorescent $\mathrm{Ca}^{2+}$ indicator targeted to mitochondria. $\mathrm{J}$ Mol Cell Cardiol 46:891-901

28. Iwatsubo K, Suzuki S, Li C, Tsunematsu T, Nakamura F, Okumura S, Sato M, Minamisawa S, Toya Y, Umemura S, Ishikawa Y (2007) Dopamine induces apoptosis in young, but not in neonatal, neurons via $\mathrm{Ca}^{2+}$-dependent signal. Am J Physiol Cell Physiol 293:C1498-C1508

29. Medina CS, Biris O, Falzone TL, Zhang X, Zimmerman AJ, Bearer EL (2016) Hippocampal to basal forebrain transport of $\mathrm{Mn}^{2+}$ is impaired by deletion of KLC1, a subunit of the conventional kinesin microtubule-based motor. Neuroimage S1053-8119:30479-30499

30. Iwatsubo K, Minamisawa S, Tsunematsu T, Nakagome M, Toya Y, Tomlinson JE, Umemura S, Scarborough RM, Levy DE, Ishikawa Y (2004) Direct inhibition of type 5 adenylyl cyclase prevents myocardial apoptosis without functional deterioration. J Biol Chem 279:40938-40945

31. Bobrowski WF, McDuffie JE, Sobocinski G, Chupka J, Olle E, Bowman A, Albassam M (2005) Comparative methods for multiplex analysis of cytokine protein expression in plasma of lipopolysaccharide-treated mice. Cytokine 32:194-198

32. Doz E, Rose S, Court N, Front S, Vasseur V, Charron S, Gilleron M, Puzo G, Fremaux I, Delneste Y, Erard F, Ryffel B, Martin OR, Quesniaux VF (2009) Mycobacterial phosphatidylinositol mannosides negatively regulate host Toll-like receptor 4, MyD88-dependent proinflammatory cytokines, and TRIF-dependent co-stimulatory molecule expression. J Biol Chem 284:23187-23196

33. Hertz AL, Bender AT, Smith KC, Gilchrist M, Amieux PS, Aderem A, Beavo JA (2009) Elevated cyclic AMP and PDE4 inhibition induce chemokine expression in human monocytederived macrophages. Proc Natl Acad Sci USA 106:21978-21983

34. Kang G, Joseph JW, Chepurny OG, Monaco M, Wheeler MB, Bos JL, Schwede F, Genieser HG, Holz GG (2003) Epac-selective cAMP analog 8-pCPT-2'-O-Me-cAMP as a stimulus for $\mathrm{Ca}^{2+}$-induced $\mathrm{Ca}^{2+}$ release and exocytosis in pancreatic $\beta$-cells. J Biol Chem 278:8279-8285 
35. Borland G, Bird RJ, Palmer TM, Yarwood SJ (2009) Activation of protein kinase $\mathrm{C} \alpha$ by EPAC1 is required for the ERK- and CCAAT/enhancer-binding protein $\beta$-dependent induction of the SOCS-3 gene by cyclic AMP in COS1 cells. J Biol Chem 284:17391-17403

36. Kinugawa K, Takahashi $\mathrm{T}$, Kohmoto O, Yao A, Aoyagi $\mathrm{T}$, Momomura S, Hirata Y, Serizawa T (1994) Nitric oxide-mediated effects of interleukin- 6 on $\left[\mathrm{Ca}^{2+}\right]_{\mathrm{i}}$ and cell contraction in cultured chick ventricular myocytes. Circ Res 75:285-295

37. Singh K, Balligand JL, Fischer TA, Smith TW, Kelly RA (1996) Regulation of cytokine-inducible nitric oxide synthase in cardiac myocytes and microvascular endothelial cells. Role of extracellular signal-regulated kinases 1 and 2 (ERK1/ERK2) and STAT1 alpha. J Biol Chem 271:1111-1117

38. Yu X, Kennedy RH, Liu SJ (2003) JAK2/STAT3, not ERK1/2, mediates interleukin-6-induced activation of inducible nitric-oxide synthase and decrease in contractility of adult ventricular myocytes. J Biol Chem 278:16304-16309

39. Yarwood SJ, Borland G, Sands WA, Palmer TM (2008) Identification of CCAAT/enhancer-binding proteins as exchange protein activated by cAMP-activated transcription factors that mediate the induction of the SOCS-3 gene. J Biol Chem 283:6843-6853

40. Nakagawa R, Naka T, Tsutsui H, Fujimoto M, Kimura A, Abe T, Seki E, Sato S, Takeuchi O, Takeda K, Akira S, Yamanishi K, Kawase I, Nakanishi K, Kishimoto T (2002) SOCS-1 participates in negative regulation of LPS responses. Immunity 17:677-687

41. Tanimoto K, Saito Y, Hamanaka I, Kuwahara K, Harada M, Takahashi N, Kawakami R, Nakagawa Y, Nakanishi M, Adachi Y, Shirakami G, Fukuda K, Yoshimura A, Nakao K (2005) SOCS1/JAB likely mediates the protective effect of cardiotrophin-1 against lipopolysaccharide-induced left ventricular dysfunction in vivo. Circ J 69:1412-1417

42. Kinjyo I, Hanada T, Inagaki-Ohara K, Mori H, Aki D, Ohnishi M, Yoshida H, Kubo M, Yoshimura A (2002) SOCS1/JAB is a negative regulator of LPS-induced macrophage activation. Immunity 17:583-591

43. Cazorla O, Lucas A, Poirier F, Lacampagne A, Lezoualc'h F (2009) The cAMP binding protein Epac regulates cardiac myofilament function. Proc Natl Acad Sci USA 106:14144-14149 